\title{
The Evaluation of Bioelectrical Activity of Pelvic Floor Muscles Depending on Probe Location: A Pilot Study
}

\author{
Tomasz Halski, ${ }^{1}$ Kuba Ptaszkowski, ${ }^{2}$ Lucyna Słupska, ${ }^{3}$ and Robert Dymarek ${ }^{4}$ \\ ${ }^{1}$ Department of Physiotherapy, Public Higher Medical Professional School in Opole, Katowicka 68, 45-060 Opole, Poland \\ ${ }^{2}$ Department of Obstetrics, Faculty of Health Science, Wroclaw Medical University, K. Bartla 5, 51-618 Wroclaw, Poland \\ ${ }^{3}$ Department of Clinical Biomechanics and Physiotherapy in Motor System Disorders, Faculty of Health Science, \\ Wroclaw Medical University, Grunwaldzka 2, 50-355 Wroclaw, Poland \\ ${ }^{4}$ Department of Nervous System Diseases, Faculty of Health Science, Wroclaw Medical University, K. Bartla 5, 51-618 Wroclaw, Poland
}

Correspondence should be addressed to Kuba Ptaszkowski; kptaszkowski@gmail.com

Received 3 November 2013; Accepted 25 November 2013

Academic Editor: Jakub Taradaj

Copyright (C) 2013 Tomasz Halski et al. This is an open access article distributed under the Creative Commons Attribution License, which permits unrestricted use, distribution, and reproduction in any medium, provided the original work is properly cited.

Objectives. The main objective was to determine how the depth of probe placement affects functional and resting bioelectrical activity of the PFM and whether the recorded signal might be dependent on the direction in which the probe is rotated. Participants. The study comprised of healthy, nulliparous women between the ages of 21 and 25. Outcome Measures. Bioelectric activity of the PFM was recorded from four locations of the vagina by surface EMG and vaginal probe. Results. There were no statistically significant differences between the results during functional sEMG activity. During resting sEMG activity, the highest bioelectrical activity of the PFM was observed in the L1 and the lowest in the L4 and a statistically significant difference between the highest and the lowest results of resting sEMG activity was observed $(P=0.0043)$. Conclusion. Different electrodes placement during functional contraction of PFM does not affect the obtained results in sEMG evaluation. In order to diagnose the highest resting activity of PFM the recording plates should be placed toward the anterior vaginal wall and distally from the introitus. However, all of the PFM have similar bioelectrical activity and it seems that these muscles could be treated as a single muscle.

\section{Introduction}

A proper assessment of the pelvic floor muscles (PFM) is an important part in the diagnosis and treatment associated with pelvic floor dysfunction, particularly with respect to urinary incontinence, faecal incontinence, or genital prolapse in women [1-9]. Methods for evaluating the strength and the endurance of the PFM are subjective transvaginal digital palpation (e.g., The Oxford Scale or The Modified Oxford Scale) and objective methods such as perineometry and electromyography (EMG) are often indicated $[1,10-$ 18]. In understanding the proper neural control as well as normal and pathological activity of the PFM a needle or surface EMG is proving to be a useful tool [19]. Increasingly common apparatus for the objective assessment of PFM is surface electromyography (sEMG) with a vaginal probe [2023]. Some studies [24-27] indicate that exact assessment of PFM function with the probe is facilitated by the fact that these muscles can behave as a single muscle during resting and functional activity. However, in accordance with the principles of evidence-based medicine we should seek to standardize measurements in terms of research equipment parameters, time, location of the measurement, and a patients position during the examination [28-35]. Reliable and consistent recording of PFM activity can be difficult, which transpires from the diversity of vaginal probes and their placement [36]. It is known that the shape and size of the probes may influence the results obtained, so it is important to optimize the type of the probe which is used to assess the strength of the PFM $[19,37]$. 


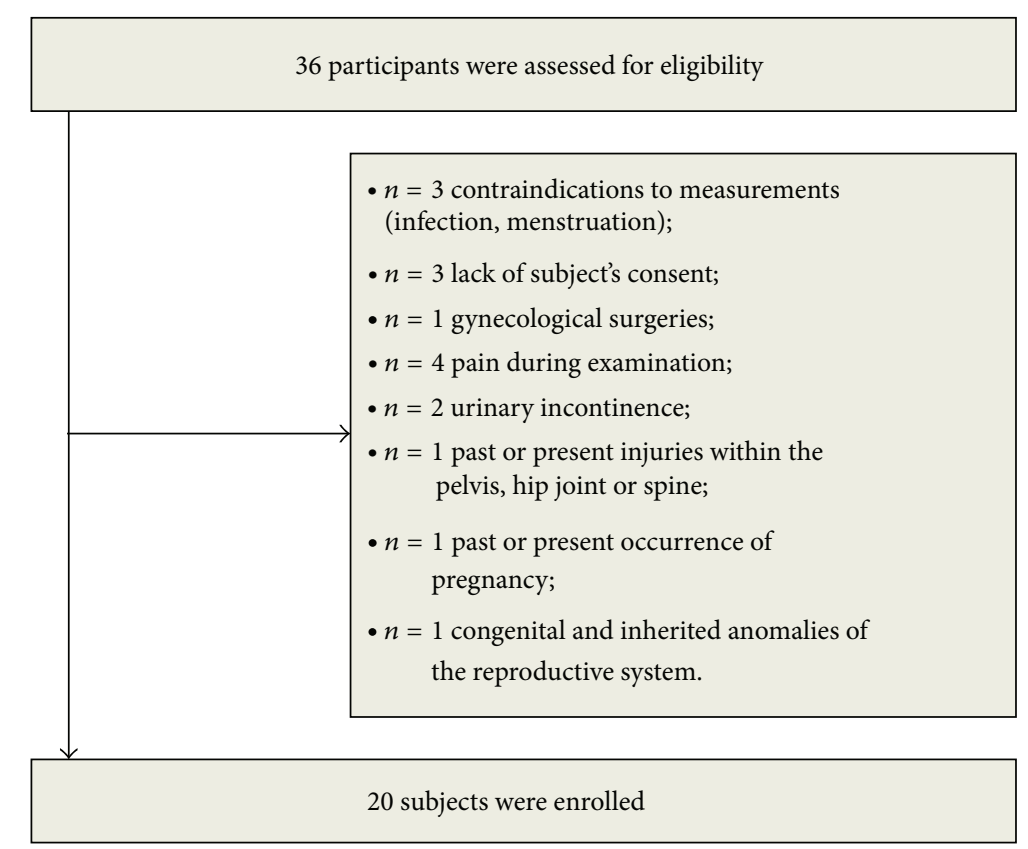

FIGURE 1: Flow diagram includes detailed information on the excluded participants.

\section{Objectives}

The wide differentiation in vaginal probes and the lack of clear methodology of their application prompted the authors to perform an evaluation of PFM bioelectrical activity corresponding to probe location. The main objective was to determine how the depth of probe placement affects the functional and resting bioelectrical activity of the PFM and whether the recorded signal might be dependent on the direction in which the probe is rotated. The probe was placed in two different orientations, toward the anterior or posterior wall of the vagina. A secondary objective was to evaluate any correlation between sEMG activities of the PFM which were measured at various areas of the vagina.

\section{Materials and Methods}

3.1. Subjects. This study was approved by the Bioethics Committee of the Wroclaw Medical University (KB-611/2012, Wroclaw, Poland) and all subjects provided written informed consent. Thirty-six healthy, nulliparous women were recruited from the Public Higher Medical Professional School population to participate. Women with a history of incontinence, gynaecological surgeries, congenital and inherited anomalies of the reproductive system, past or present injuries within the pelvis, hip joint or spine, and pregnancy were excluded, as well as women with contraindications to measurements (such as infection and menstruation) (Figure 1). Finally, the study comprised of twenty volunteers between the ages of 21 and 25 $(\bar{x}=22.3$ years, $\mathrm{SD}=1.28$ years $)$.

3.2. Electromyography. The electromyographic signal was registered by a dual-channel sEMG NeuroTrac ETS device integrated with computer software for digital analysis and report creation (Verity Medical Ltd., UK). This device is characterized by an amplitude range of $0.2-2000 \mu \mathrm{V}$ RMS continuous in the frequency band of $2-100 \mathrm{~Hz}$ and pulse width from 50 to $450 \mu \mathrm{S}$ for recording signals generated by muscles. Device sensitivity is established at a level $0.1 \mu \mathrm{V}$ ( $4 \%$ accuracy; readings $\pm 0.3 \mathrm{mV}$ at $200 \mathrm{~Hz}$ ), with selectable bandpass filter ( $3 \mathrm{db}$ bandwidth) and $50 \mathrm{~Hz}$ notch filter ( $33 \mathrm{dbs} ; 0.1 \%$ accuracy). The analogue signal recorded by the sEMG electrodes was amplified, filtered, and subsequently transformed into a digital signal. Such signal facilitated statistical analysis of acquired results and allowed for data representation in a graphical form. Mean values of muscle bioelectrical activity were given according to root mean square algorithm (RMS) [28, 38-40]. The monopolar, selfadhesive reference electrode was placed on the anterior superior iliac spine.

3.3. Probe Descriptions. To investigate the pelvic floor muscle activity we used Vaginal Probe Periprobe Optima 3 (Sugar International, France) with 3 independent, hemispherical, nickel-free electrodes (recording plates). The top (electrode A), the middle (electrode B), and the bottom (electrode C) electrodes of the probe are three detection surfaces. The probe has a total length of $12 \mathrm{~cm}$ and total weight of $21 \mathrm{~g}$. The circumference of the top electrode is $7.5 \mathrm{~cm}$. The circumference of the middle and the bottom electrode is $6.5 \mathrm{~cm}$. The distance between the electrodes is $3.3 \mathrm{~cm}$. The position of the probe was determined by a mark to be placed in line with the introitus of the vagina. The middle of electrode $\mathrm{A}$ is $8.7 \mathrm{~cm}$ from the introitus, the middle of electrode $B$ is $5.4 \mathrm{~cm}$ from the introitus, and the middle of electrode $\mathrm{C}$ is $2.1 \mathrm{~cm}$ from the introitus. 


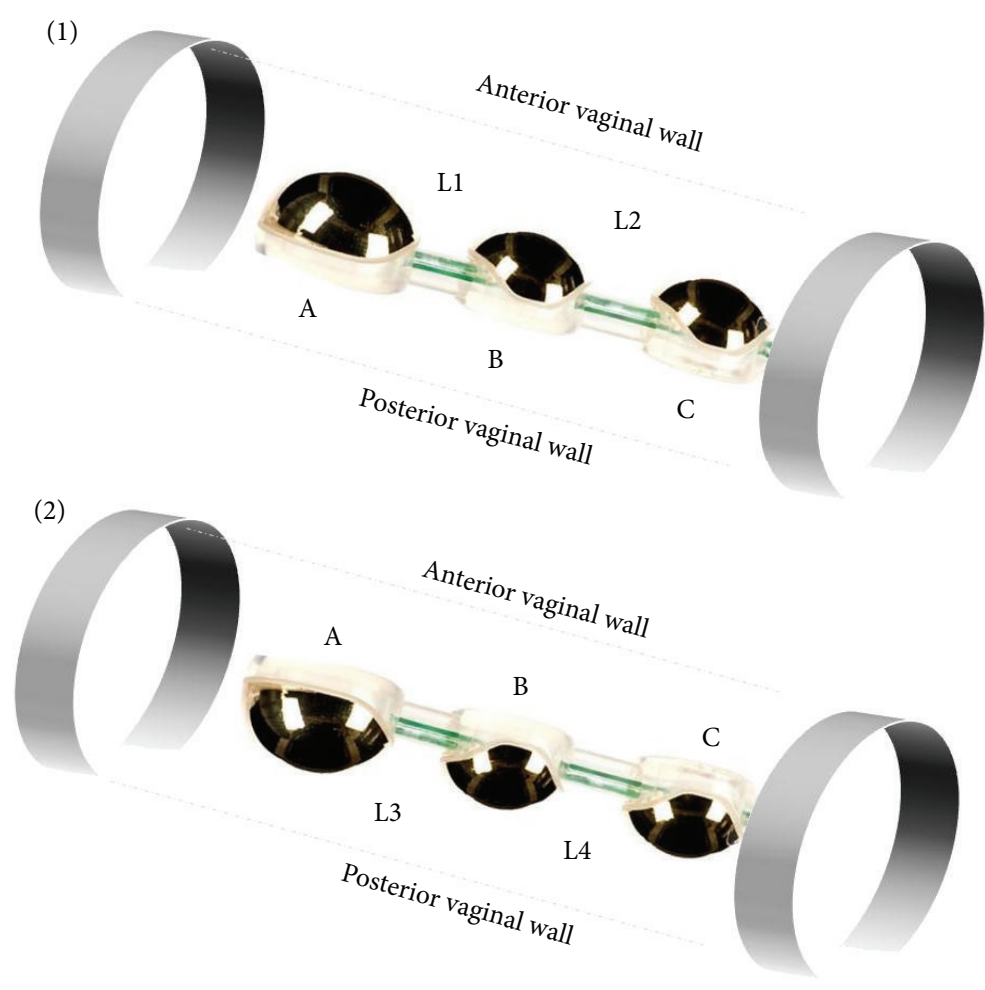

FIGURE 2: Location of the probe during measuring of PFM activity. (1) The probe was toward the anterior wall of the vagina. (2) The probe was toward the posterior wall of the vagina; L1, L2, L3, and L4: locations 1, 2, 3, and 4; A: the top electrode, B: the middle electrode, and C: the bottom electrode.

3.4. Experimental Protocol. Measurement of electrical activity of the PFM was assessed in a standing position. Prior to measurements, each participant was instructed how to perform an isolated PFM contraction. Resting and functional sEMG activity (in microvolts $\mu \mathrm{V}$ ) were recorded. All of the women participating in this study were asked to contract the PFM as hard as possible for five seconds (functional activity). The contractions were repeated five times with five-second break between each contraction (resting activity). The probe was placed in two different orientations and measurement was performed when the probe was toward the anterior wall of the vagina and afterward toward the posterior wall. Bioelectric activity of the PFM was recorded from four locations (Figure 2).

Location 1 (L1) is the circuit between electrodes A and $\mathrm{B}$ towards anterior wall of the vagina.

Location 2 (L2) is the circuit between electrodes B and $\mathrm{C}$ towards anterior wall of the vagina.

Location 3 (L3) is the circuit between electrodes A and $B$ towards posterior wall of the vagina.

Location 4 (L4) is the circuit between electrodes B and $\mathrm{C}$ towards posterior wall of the vagina.

3.5. Statistical Analysis. Statistical analysis was performed using Statistica 10. Analysis of variance (ANOVA) of KruskalWallis was used to examine the difference between the sEMG activity in each location. A value of $P<0.05$ was considered statistically significant. The differences between measurements obtained during resting and during functional sEMG activity were compared. In addition, Spearman correlation was made to show the relationship between the variables.

\section{Results}

There were no statistically significant differences between the results during functional sEMG activity (Figure 3). During resting sEMG activity, the highest bioelectrical activity of the PFM was observed in $\mathrm{L} 1(\bar{x}=2.4 \mu \mathrm{V}$, min-max: $1.3-4.0 \mu \mathrm{V}$, $\mathrm{SD}=0.69 \mu \mathrm{V})$ and the lowest in the $\mathrm{L} 4(\bar{x}=1.7 \mu \mathrm{V}$, minmax: $0.9-3.2 \mu \mathrm{V} ; \mathrm{SD}=0.63 \mu \mathrm{V})$. A statistically significant difference between the highest and the lowest results of resting sEMG activity was observed $(P=0.0043)$ (Figure 4$)$. Among other results, no statistically significant differences were registered.

In the study population, a statistically significant correlation was found for all analyzed variables. The correlations are presented in Tables 1 (for resting sEMG activity) and 2 (for functional sEMG activity). Spearman analysis showed statistical correlation between the results of PFM functional activity of four locations (Table 1): between L1 and L2: $P=$ 0.0008, $r=0.69$; L1 and L3: $P=0.0000, r=0.85$; L1 and L4: $P=0.0012, r=0.67$; L2 and L3: $P=0.0000, r=0.83$; L2 and L4: $P=0.0000, r=0.89$; L3 and L4: $P=0.0000$, 
TABLE 1: The correlation between the results of PFM activity of four locations-functional sEMG activity.

\begin{tabular}{|c|c|c|c|c|}
\hline \multicolumn{5}{|c|}{ Functional sEMG activity of PFM } \\
\hline & L1 & L2 & L3 & $\mathrm{L} 4$ \\
\hline L1 & - & $\begin{array}{c}r=0.69 \\
P=0.0008\end{array}$ & $\begin{array}{c}r=0.85 \\
P=0.0000\end{array}$ & $\begin{array}{c}r=0.67 \\
P=0.0012\end{array}$ \\
\hline $\mathrm{L} 2$ & $\begin{array}{c}r=0.69 \\
P=0.0008\end{array}$ & - & $\begin{array}{c}r=0.83 \\
P=0.0000\end{array}$ & $\begin{array}{c}r=0.89 \\
P=0.0000\end{array}$ \\
\hline L3 & $\begin{array}{c}r=0.85 \\
P=0.0000\end{array}$ & $\begin{array}{c}r=0.83 \\
P=0.0000\end{array}$ & - & $\begin{array}{c}r=0.87 \\
P=0.0000\end{array}$ \\
\hline L4 & $\begin{array}{c}r=0.67 \\
P=0.0012\end{array}$ & $\begin{array}{c}r=0.89 \\
P=0.0000\end{array}$ & $\begin{array}{c}r=0.87 \\
P=0.0000\end{array}$ & - \\
\hline
\end{tabular}

TABLE 2: The correlation between the results of PFM activity of four locations-resting sEMG activity.

\begin{tabular}{lcccc}
\hline & & Resting sEMG activity of PFM & & L3 \\
L1 & L2 & $r=0.64$ & $r=0.53$ \\
L1 & - & $r=0.60$ & $P=0.0022$ & $P=0.0173$ \\
L2 & $r=0.60$ & $P=0.0052$ & $r=0.68$ & $r=0.81$ \\
& $P=0.0052$ & - & $P=0.0010$ & $P=0.0000$ \\
L3 & $r=0.64$ & $r=0.68$ & - & $r=0.83$ \\
& $P=0.0022$ & $P=0.0010$ & $r=0.83$ & -0.0000 \\
L4 & $r=0.53$ & $r=0.81$ & $P=0.0000$ & - \\
\hline
\end{tabular}

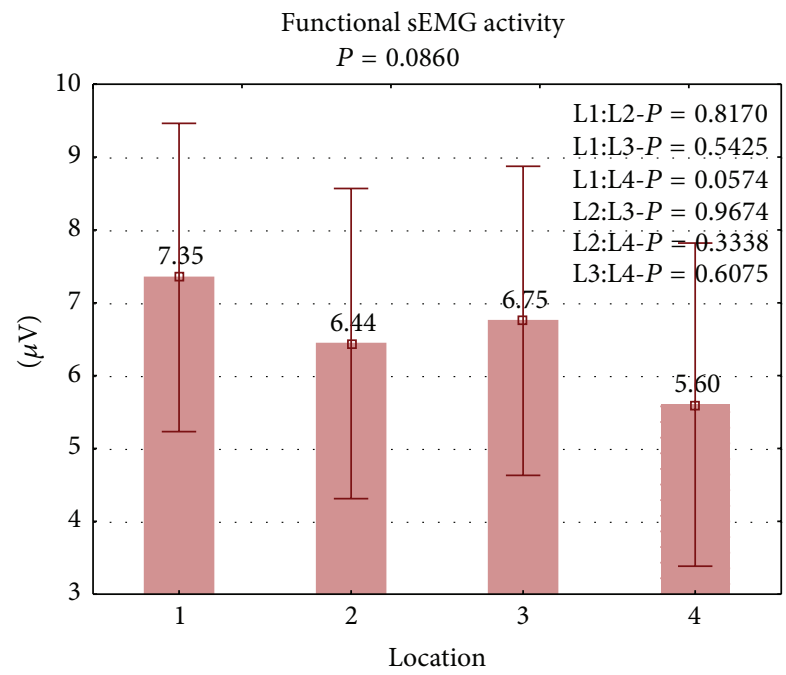

Mean

I Mean $\pm \mathrm{SD}$

FIGURE 3: The results of PFM activity during functional sEMG activity in four locations.

$r=0.87$. We also observed statistical correlation between the results of PFM resting activity (Table 2): between L1 and L2: $P=0.0052, r=0.60 ; \mathrm{L} 1$ and L3: $P=0.0022, r=0.64 ; \mathrm{L} 1$ and L4: $P=0.0173, r=0.53$; L2 and L3: $P=0.0010, r=0.68$; L2 and L4: $P=0.0000, r=0.81$; 3 and L4: $P=0.0000, r=0.83$.

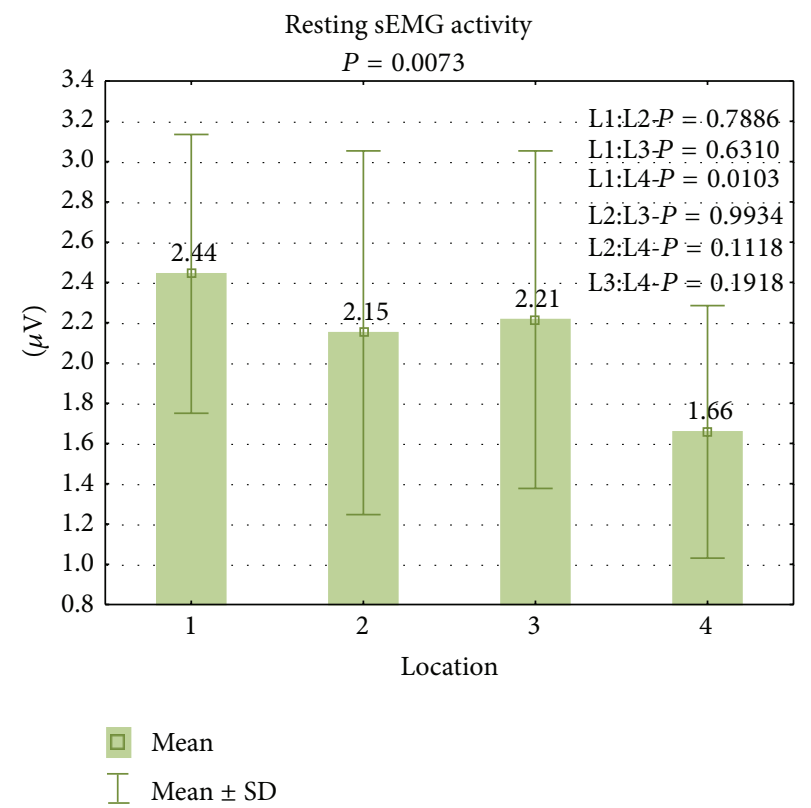

FIGURE 4: The results of PFM activity during resting sEMG activity in four locations.

\section{Discussion}

This study tries to determine the evaluation of bioelectrical activity of the PFM according to probe location. The factors which were taken into consideration are depth of electrode 
placement and their orientation. Functional and resting sEMG activity was assessed with an Optima 3 vaginal probe.

The presented results pertain to the diagnostics of PFM activity and they confirm that the activity depends on the area where recording plates are located. Long probes have recording plates which can record the sEMG signal from areas of vaginal wall located distal to the vaginal introitus. Shorter probes collect the activity from proximal locations.

Voorham van der Zalm et al. [36] conducted similar assessment of the location of different types of electrodes. In their study they used five common probes which differed in shape, length, and width of the recording plates as well as in circumference, length of the probe, and place of insertion of the probe. The position of recording plates was evaluated in relation to puborectal muscles and examined by ultrasound. Although the study did not have a representative research group, on the basis of the results the authors recognize the value in conducting further studies in order to optimize the probes used.

Bø et al. [37] also noticed that the size and location of vaginal probes have an impact on the obtained results. In the assessment of the PFM they used two types of vaginal probes: the Camtech Squeez meter (length: $6.7 \mathrm{~cm}$, diameter: $1.7 \mathrm{~cm}$, location: the middle of the balloon was $3.5 \mathrm{~cm}$ from the introitus) and the Peritron (length: $10.8 \mathrm{~cm}$, diameter: $2.8 \mathrm{~cm}$, location: $0.5-1 \mathrm{~cm}$ of the probe was visible outside the introitus). The results of vaginal squeeze pressure varied depending on the type of vaginal probe used in the study. Therefore, the use of various electrodes in the studies does not allow for effective comparison of results.

A clinician should be able to match the appropriate type of probe depending on the therapeutic purpose (specifically in electrical stimulation). This is due to another feature of vaginal probes. In addition to their usage in the evaluation of PFM activity, they can be applied in the treatment of urinary incontinence. For example, in therapy for urge incontinence, the stimulation should include afferent nerve fibres of the plexus pelvicus and the pudendal nerve. In cases where the patient suffers from stress incontinence, electrical stimulation should influence the external sphincter and pelvic floor muscles. Thus, size, shape, length, width, and circumference play a significant role both in the diagnostics and in the therapy of urinary incontinence [36, 41, 42].

The distribution of forces acting on the vagina following pelvic floor contractions is varied which was confirmed by our results. Although, most of the results are not statistically significant, higher bioelectric activity was observed more distally from the introitus and on the anterior wall of the vagina. Constantinous and Omata's study [43] is another investigation into the distribution of forces acting on the vagina. They evaluated the distribution of anisotropic forces on the vagina following voluntary and reflex pelvic floor contractions. The probe with four pairs of force and displacement sensors was used to measure the pelvic floor closure force. The researchers observed significantly higher maximum forces of contraction in the anterior aspects of the vagina during reflex pelvic floor contractions. The unequal distribution of forces in the vaginal walls is the subject of other similar studies [44-47].
However Shafik's study [24] demonstrates that all of the pelvic floor muscles behave as one muscle since they contract or relax collectively, which was also noticed in this study in strong correlation between measurements from particular localizations. He explains this phenomenon by referring to the origin of pelvic floor muscles. External anal (EAS) and urethral sphincters (EUS) as well as the bulbocavernosus muscle (BC) arise from the puborectalis muscle (PR). Though the levator ani (pubococcygeus) is not descended from the puborectalis muscle, it shares with it its innervations through the pudendal nerve. Stimulation of sensory fibres of the pudendal nerve activates reflex contractions of the stimulated muscle and of all of the muscles supplied by this nerve. Nonetheless, he also confirmed a voluntary selective muscle activity and that each individual pelvic floor muscle can act independently of the others.

The results prompt for further studies, in order to find research tools for more accurate assessment of pelvic floor muscles, in addition to the evaluation by sEMG or perineometer. It may be very meaningful to diagnose the PFM using ultrasound or MRI. Furthermore, there is a need to strictly determine the methodology of measurements and the type of equipment used.

Attention should be given to the practical implications of this study. The clinical reliability and accuracy of PFM measurements are indeterminate and should be reevaluated. The study is highlighting aspects of the objectification of both the measurement and the measurement tools. In this pilot study the authors used a probe which has not yet been the subject of a randomized trial and which assessed the bioelectrical activity from various localizations of the vagina.

\section{Limitation of the Study}

Some limitations of the study were the small number of participants, no measurements in patients with pelvic floor dysfunction, and the lack of more sensitive multichannel sEMG. This study will be continued among patients with the pelvic floor dysfunction and complemented by measurements using different types of probes.

\section{Conclusion}

Different electrodes placement during functional contraction of the PFM does not affect the obtained results in sEMG evaluation. In order to diagnose the highest resting activity of the PFM the recording plates could be placed toward the anterior vaginal wall and distally from the introitus. However, all of the PFM have similar bioelectrical activity and it seems that these muscles could be treated as a single muscle. Therefore, it is appropriate to continue to conduct measurements of bioelectrical activity of the PFM, depending on the placement and the type of probes. Further experimental research should include a larger number of participants as well as individuals with lower urinary tract symptoms.

\section{Conflict of Interests}

There is no conflict of interests. 


\section{References}

[1] A. Devreese, F. Staes, W. De Weerdt et al., "Clinical evaluation of pelvic floor muscle function in continent and incontinent women," Neurourology and Urodynamics, vol. 23, no. 3, pp. 190197, 2004.

[2] K. Bø, "Pelvic floor muscle training is effective in treatment of female stress urinary incontinence, but how does it work?" International Urogynecology Journal and Pelvic Floor Dysfunction, vol. 15, no. 2, pp. 76-84, 2004.

[3] D. D. Chmielewska, K. Kwasna, M. Piecha et al., "Selected methods of conservative treatment of stress urinary incontinence: current views. Part 1," Menopause Review, vol. 4, pp. 264-268, 2012.

[4] P. Abrams, L. Cardozo, M. Fall et al., "The standardisation of terminology of lower urinary tract function: report from the standardisation sub-committee of the international continence society," Neurourology and Urodynamics, vol. 21, no. 2, pp. 167178, 2002.

[5] P. Dolibog, A. Franek, J. Taradaj et al., "A randomized, controlled clinical pilot study comparing three types of compression therapy to treat venous leg ulcers in patients with superficial and/or segmental deep venous reflux," Ostomy Wound Management, vol. 59, no. 8, pp. 22-30, 2013.

[6] E. J. Hay-Smith and C. Dumoulin, "Pelvic floor muscle training versus no treatment, or inactive control treatments, for urinary incontinence in women," Cochrane Database of Systematic Reviews, vol. 25, no. 1, Article ID CD005654, 2006.

[7] S. Mørkved, K. Bø, and T. Fjørtoft, "Effect of adding biofeedback to pelvic floor muscle training to treat urodynamic stress incontinence," Obstetrics and Gynecology, vol. 100, no. 4, pp. 730739, 2002.

[8] J. Taradaj, T. Halski, M. Kucharzewski et al., "Effect of laser irradiation at different wavelengths $(940,808$, and $658 \mathrm{~nm})$ on pressure ulcer healing: results from a clinical study," EvidenceBased Complementary and Alternative Medicine, vol. 2013, Article ID 960240, 8 pages, 2013.

[9] K. Kassolik, D. Kurpas, W. Andrzejewski, I. Wilk, and M. Swiatek, "The effectiveness of massage in stress urinary incontinence: case study," Rehabilitation Nursing, vol. 38, no. 6, pp. 306-314.

[10] U. M. Peschers, A. Gingelmaier, K. Jundt, B. Leib, and T. Dimpfl, "Evaluation of pelvic floor muscle strength using four different techniques," International Urogynecology Journal and Pelvic Floor Dysfunction, vol. 12, no. 1, pp. 27-30, 2001.

[11] K. Bo, "Vaginal weight cones. Theoretical framework: effect on pelvic floor muscle strength and female stress urinary incontinence," Acta Obstetricia et Gynecologica Scandinavica, vol. 74, no. 2, pp. 87-92, 1995.

[12] P. K. Sand, D. A. Richardson, D. R. Staskin et al., "Pelvic floor electrical stimulation in the treatment of genuine stress incontinence: a multicenter, placebo-controlled trial," The American Journal of Obstetrics and Gynecology, vol. 173, no. 1, pp. 72-79, 1995.

[13] A. Franek, R. Kostur, A. Polak et al., "Using high-voltage electrical stimulation in the treatment of recalcitrant pressure ulcers: results of a randomized, controlled clinical study," Ostomy Wound Management, vol. 58, no. 3, pp. 30-44, 2012.

[14] P. B. Neumann, K. A. Grimmer, and Y. Deenadayalan, "Pelvic floor muscle training and adjunctive therapies for the treatment of stress urinary incontinence in women: a systematic review," BMC Women's Health, vol. 6, article 11, 2006.
[15] J. Taradaj, A. Franek, E. Blaszczak et al., "Physical therapy in the treatment of venous leg ulcers: biophysical mechanisms," Wounds, vol. 24, no. 5, pp. 138-145, 2012.

[16] K. Kassolik, W. Andrzejewski, M. Brzozowski et al., "Medical massage as a physiotherapeutic method in benign prostatic hyperplasia in men," Journal of Bodywork and Movement Therapies, vol. 11, no. 2, pp. 121-128, 2007.

[17] D. D. Chmielewska, M. Piecha, K. Kwasna et al., "Urinary incontinence: a problem of the modern woman," Menopause Review, vol. 5, pp. 378-384, 2013.

[18] B. M. Al-Ali, R. Shamloul, G. C. Hutterer et al., "Sexual function in women with stress urinary incontinence treated with the SPARC sling system," BioMed Research International, vol. 2013, Article ID 957547, 6 pages, 2013.

[19] P. Enck and D. B. Vodušek, "Electromyography of pelvic floor muscles," Journal of Electromyography and Kinesiology, vol. 16, no. 6, pp. 568-577, 2006.

[20] C. Auchincloss and L. McLean, "Does the presence of a vaginal probe alter pelvic floor muscle activation in young, continent women?" Journal of Electromyography and Kinesiology, vol. 22, no. 6, pp. 1003-1009, 2012.

[21] K. Kwasna, D. Chmielewska, M. Piecha et al., "Physiotherapy treatment of urinary stress incontinence in women. Part 2," Menopause Review, vol. 11, no. 5, pp. 372-375, 2012.

[22] D. Alewijnse, J. F. M. Metsemakers, I. E. P. E. Mesters, and B. Van den Borne, "Effectiveness of pelvic floor muscle exercise therapy supplemented with a health education program to promote long-term adherence among women with urinary incontinence," Neurourology and Urodynamics, vol. 22, no. 4, pp. 284-295, 2003.

[23] P. Aukee, P. Immonen, D. E. Laaksonen, P. Laippala, J. Penttinen, and O. Airaksinen, "The effect of home biofeedback training on stress incontinence," Acta Obstetricia et Gynecologica Scandinavica, vol. 83, no. 10, pp. 973-977, 2004.

[24] A. Shafik, "A new concept of the anatomy of the anal sphincter mechanism and the physiology of defecation: mass contraction of the pelvic floor muscles," International Urogynecology Journal and Pelvic Floor Dysfunction, vol. 9, no. 1, pp. 28-32, 1998.

[25] C. E. Constantinou, G. Hvistendahl, A. Ryhammer, L. L. Nagel, and J. C. Djurhuus, "Determining the displacement of the pelvic floor and pelvic organs during voluntary contractions using magnetic resonance imaging in younger and older women," BJU International, vol. 90, no. 4, pp. 408-414, 2002.

[26] S. P. Vasavada, C. V. Comiter, and S. Raz, "Incisionless pubovaginal fascial sling using transvaginal bone anchors for the treatment of stress urinary incontinence," TheScientific WorldJournal, vol. 4, pp. 357-363, 2004.

[27] S. Shaikh, E. K. Ong, K. Glavind, J. Cook, and J. M. N'Dow, "Mechanical devices for urinary incontinence in women," Cochrane Database of Systematic Reviews, no. 2, Article ID CD001756, 2006.

[28] A. Burden, "How should we normalize electromyograms obtained from healthy participants? What we have learned from over 25 years of research," Journal of Electromyography and Kinesiology, vol. 20, no. 6, pp. 1023-1035, 2010.

[29] J. Taradaj, A. Franek, L. Cierpka et al., "Early and long-term results of physical methods in the treatment of venous leg ulcers: randomized controlled trial," Phlebology, vol. 26, no. 6, pp. 237$245,2011$. 
[30] K. F. Hunter, K. N. Moore, and C. M. A. Glazener, "Conservative management for postprostatectomy urinary incontinence," Cochrane Database of Systematic Reviews, vol. 2, no. 2, Article ID CD001843, 2007.

[31] J. Chen, H. Horng, W. Lin, and K. Tsai, "Noninvasive wireless sensor PFMT device for pelvic floor muscle training," International Journal of Distributed Sensor Networks, vol. 2012, 7 pages, 2012.

[32] D. M. Morgan, R. L. Dunn, J. T. Stoffel et al., "Are persistent or recurrent symptoms of urinary incontinence after surgery associated with adverse effects on sexual activity or function?" International Urogynecology Journal and Pelvic Floor Dysfunction, vol. 19, no. 4, pp. 509-515, 2008.

[33] K. L. Burgio, K. A. Matthews, and B. T. Engel, "Prevalence, incidence and correlates of urinary incontinence in healthy, middleaged women," Journal of Urology, vol. 146, no. 5, pp. 1255-1259, 1991.

[34] J. Taradaj, A. Franek, L. Brzezinska-Wcislo et al., "The use of therapeutic ultrasound in venous leg ulcers: a randomized, controlled clinical trial," Phlebology, vol. 23, no. 4, pp. 178-183, 2008.

[35] A. Mostafa, J. N’Dow, and M. Abdel-Fattah, "Factors influencing women's decision to participate or not in a surgical randomised controlled trial for surgical treatment of female stress urinary incontinence," BioMed Research International, vol. 2013, Article ID 139813, 8 pages, 2013.

[36] P. Voorham-van der Zalm, R. Pelger, I. van Heeswijk-Faase et al., "Placement of probes in electrostimulation and biofeedback training in pelvic floor dysfunction," Acta Obstetricia et Gynecologica Scandinavica, vol. 85, no. 7, pp. 850-855, 2006.

[37] K. Bø, R. Raastad, and H. B. Finckenhagen, "Does the size of the vaginal probe affect measurement of pelvic floor muscle strength?" Acta Obstetricia et Gynecologica Scandinavica, vol. 84, no. 2, pp. 129-133, 2005.

[38] F. Zaheer, S. H. Roy, and C. J. De Luca, "Preferred sensor sites for surface EMG signal decomposition," Physiological Measurement, vol. 33, no. 2, pp. 195-206, 2012.

[39] E. Bł-aszczak, A. Franek, J. Taradaj, J. Widuchowski, and J. Klimczak, "Assessment of the efficacy and safety of low frequency, low intensity magnetic fields in patients after knee endoprosthesis plasty. Part 1: in vitro safety," Bioelectromagnetics, vol. 30, no. 2, pp. 159-162, 2009.

[40] E. Błaszczak, A. Franek, J. Taradaj, J. Widuchowski, and J. Klimczak, "Assessment of the efficacy and safety of low frequency, low intensity magnetic fields in patients after knee endoprosthesis plasty. Part 2: a clinical study," Bioelectromagnetics, vol. 30, no. 2, pp. 152-158, 2009.

[41] M. Fall and S. Lindstrom, "Functional electrical stimulation: physiological basis and clinical principles," International Urogynecology Journal, vol. 5, no. 5, pp. 296-304, 1994.

[42] A. C. Diokno, B. M. Brock, A. Regula Herzog, and J. Bromberg, "Medical correlates of urinary incontinence in the elderly," Urology, vol. 36, no. 2, pp. 129-138, 1990.

[43] C. E. Constantinou and S. Omata, "Direction sensitive sensor probe for the evaluation of voluntary and reflex pelvic floor contractions," Neurourology and Urodynamics, vol. 26, no. 3, pp. 386-391, 2007.

[44] Q. Peng, R. C. Jones, and C. E. Constantinou, "2D ultrasound image processing in identifying responses of urogenital structures to pelvic floor muscle activity," Annals of Biomedical Engineering, vol. 34, no. 3, pp. 477-493, 2006.
[45] C. S. Saleme, D. N. Rocha, S. del Vecchio, A. L. Silva Filho, and M. Pinotti, "Multidirectional pelvic floor muscle strength measurement," Annals of Biomedical Engineering, vol. 37, no. 8, pp. 1594-1600, 2009.

[46] J. Taradaj, A. Franek, E. Blaszczak et al., "Using physical modalities In the treatment of venous leg ulcers-a 14 year comparative clinical study," Wounds, vol. 24, no. 8, pp. 215-226, 2012.

[47] K. Shishido, Q. Peng, R. Jones, S. Omata, and C. E. Constantinou, "Influence of pelvic floor muscle contraction on the profile of vaginal closure pressure in continent and stress urinary incontinent women," Journal of Urology, vol. 179, no. 5, pp. 19171922, 2008. 


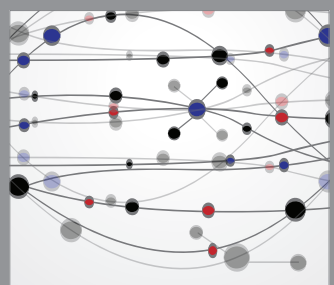

The Scientific World Journal
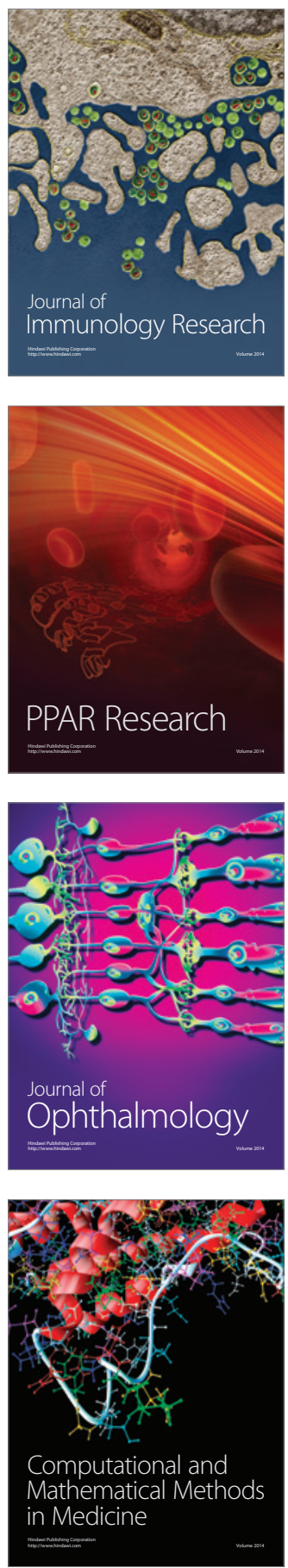

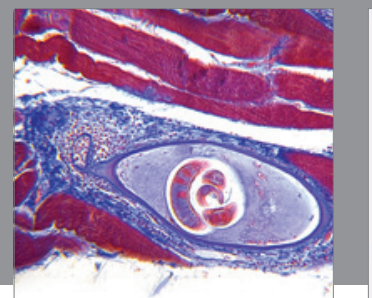

Gastroenterology

Research and Practice
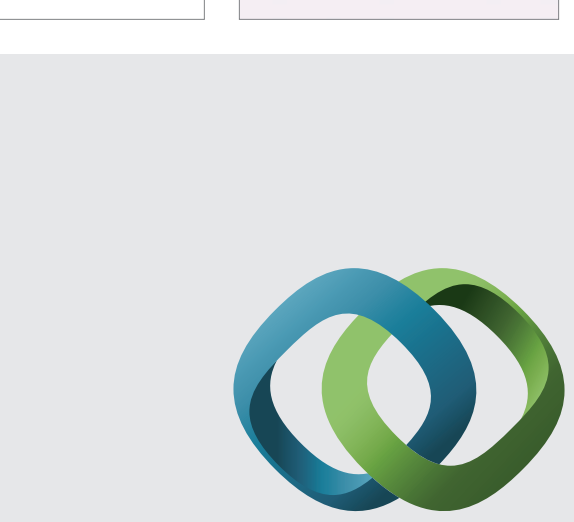

\section{Hindawi}

Submit your manuscripts at

http://www.hindawi.com
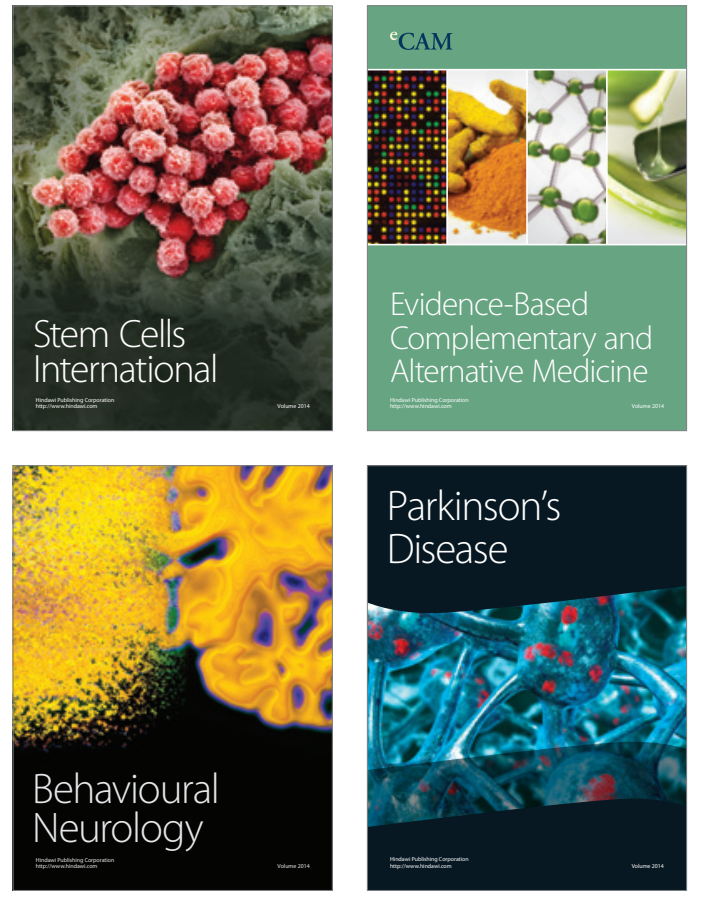
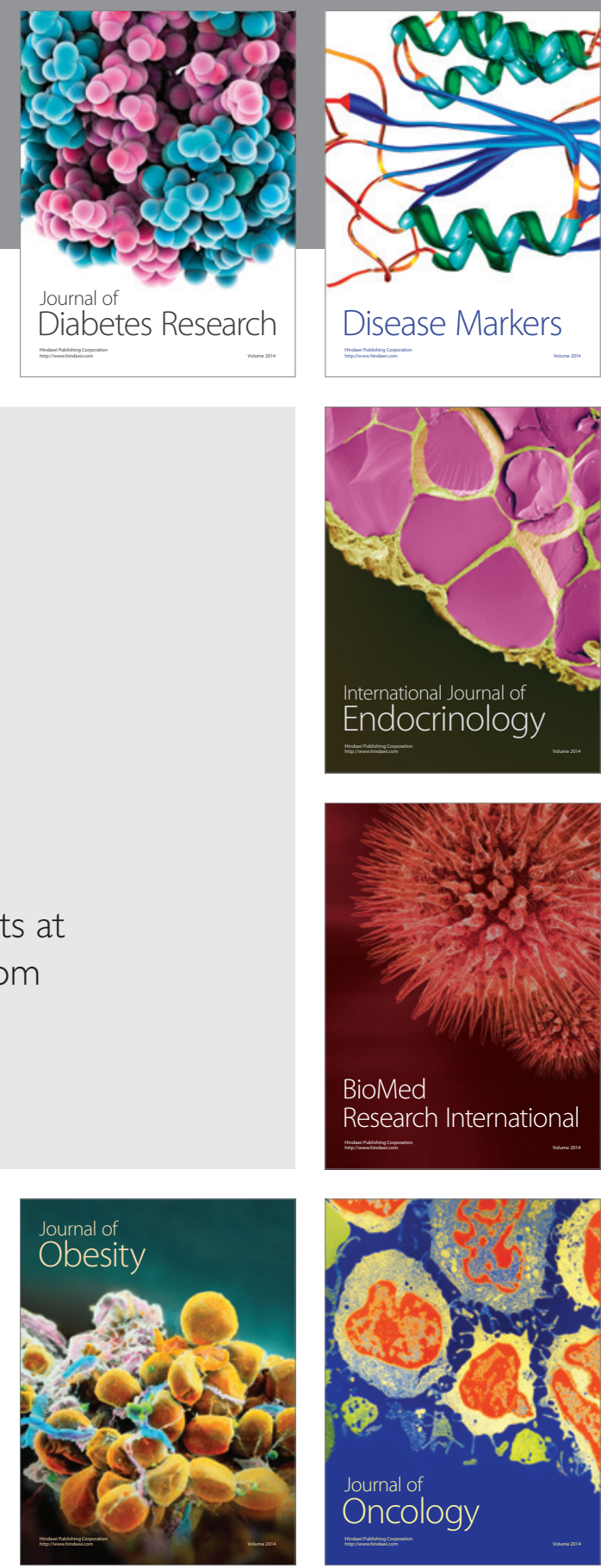

Disease Markers
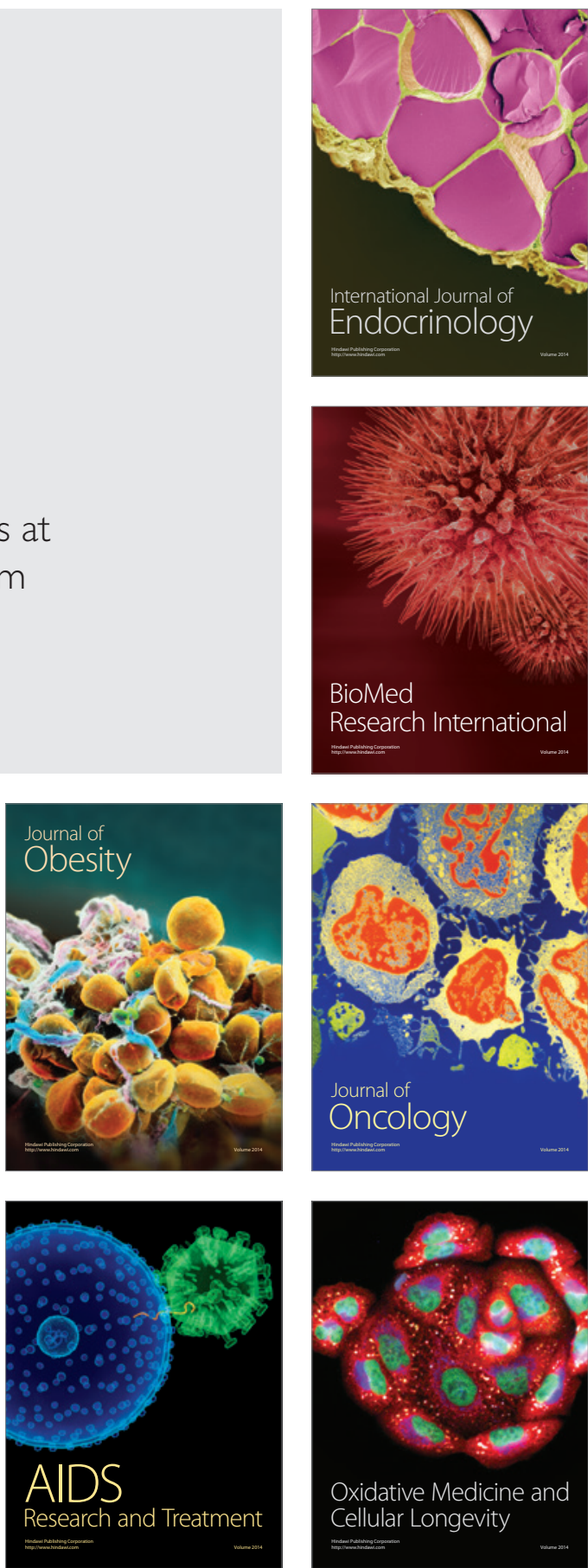